PAPER

\title{
Email triage of new neurological outpatient referrals from general practice
}

\author{
V Patterson, J Humphreys, R Chua
}

J Neurol Neurosurg Psychiatry 2004;75:617-620. doi: 10.1136/jnnp.2003.024489

See end of article for authors' affiliations

.....................

Correspondence to:

Dr V Patterson,

Department of Neurology, Neurology Ward 4E,

Royal Victoria Hospital,

Grosvenor Road, Belfast

BT1 2 6BA, UK;

tele.neuro@

royalhospitals.n-i.nhs.uk

Received 29 July 2003

Accepted 23 August 2003

....................
Objectives: To determine whether an email triage system between general practitioners and a neurologist for new outpatient referrals is feasible, acceptable, efficient, safe, and effective.

Methods: This was a prospective single cohort study on the interface between primary care practitioners and the neurology clinic of a district general hospital. Seventy six consecutive patients with neurological symptoms from nine GPs, for whom a specialist opinion was deemed necessary, were entered in the study. The number of participants managed without clinic attendance and the reduction in neurologist's time compared with conventional consultation was measured, as was death, other specialist referral, and change in diagnosis in the 6 months after episode completion. The acceptability for GPs was ascertained by questionnaire.

Results: Forty three per cent of participants required a clinic appointment, $45 \%$ were managed by email advice alone, and $12 \%$ by email plus investigations. GP satisfaction was high. Forty four per cent of the neurologist's time was saved compared with conventional consultation. No deaths or significant changes in diagnosis were recorded during the 6 month follow up period.

Conclusions: Email triage is feasible, acceptable to GPs, and safe. It has the potential for making the practice of neurologists more efficient, and this needs to be tested in a larger randomised study.
$\mathrm{T}$ he waiting time for a patient referred to a neurologist in the UK and Ireland is often greater than 6 months, leading to frustration for patients and their referring general practitioners (GPs). The obvious solution to this is the appointment of more consultant neurologists as envisaged by the Association of British Neurologists. ${ }^{12}$ Although this offers improvement for the medium term, other solutions are needed for the short term.

We investigated whether we could improve the present system by using email to triage GP referrals to a neurologist. Email has many advantages over conventional letters, but the most important is the potential for rapid reply, enabling GPs to have a specialist opinion within hours. With the modernisation of the NHS, the required technology is becoming more prevalent in GPs' surgeries. There is some good evidence from a Finnish study that email can indeed make the primary-secondary care interface more efficient. ${ }^{3}$ We have also used email consultations with a rehabilitation hospital in Bangladesh for very complicated neurological patients and found the system to be surprisingly effective and acceptable. $^{4}$

To introduce such a novel method of practice required a study of its feasibility, acceptability, effectiveness, and efficiency, and especially its safety.

\section{METHODS}

\section{Participants}

Nine GPs from three general practices in three towns in the west of Northern Ireland, (Lisnaskea, Irvinestown, and Castlederg) were selected for study for two reasons: $(a)$ one of the authors (VP) was the visiting neurologist to this area (approximately 1 day/week), and $(b)$ all GPs had and were prepared to use email, and agreed to refer all their patients with neurological symptoms requiring hospital referral by email. The study was managed from the Erne Hospital in Enniskillen, part of Sperrin Lakeland Health and Social Care Trust.

\section{Email system}

A structured form was devised for GPs to refer patients (fig l). This set out the required history and examination and was either sent as an email attachment or incorporated in the body text of the email.

GPs used their home email address to start the study but later email addresses were provided for them by their local health board. Emails were sent to two email addresses for the neurologist; both the hospital (NHS) address and home address, to give the best chance for a reply within 48 hours.

Patient confidentiality was preserved by using a unique patient identification number on the subject bar of the email. For example, LIS 018 would have been the 18th patient referred from the Lisnaskea practice. A similar method had been used in previous studies. ${ }^{5}$ Later in the study, a unique patient client identifier (UPCI) number was also added to the subject bar. The UPCI linked with the hospital information system and made administration much easier if a hospital appointment was required. Sperrin Lakeland Health and Social Care Trust is a pilot site for UPCI numbers, which will be introduced throughout the Northern Ireland Health Service in 2004.

\section{Process}

The pathway for referral is shown in fig 2 . When the neurologist received the email referral he decided whether advice alone was appropriate, whether investigations were needed, or whether a clinic visit was necessary. When the investigation results were available, either a clinic appointment was made or further advice given.

Abbreviations: GP, general practitioner; UPCI, unique patient client identifier 


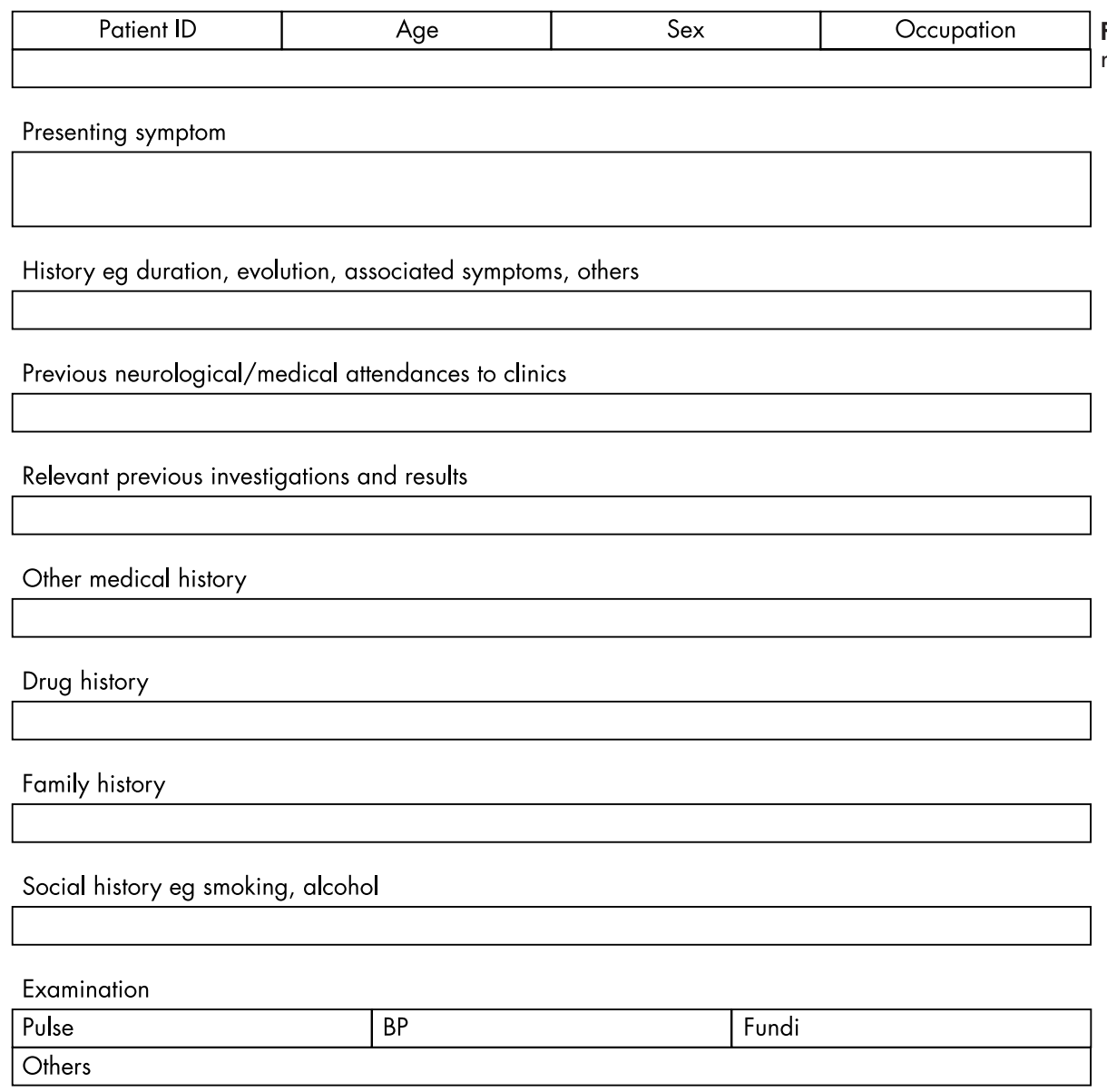

\section{Outcome measures}

We recorded basic demographic data on each referral (age, sex, main symptom, and final diagnosis), information on investigations performed, and whether the patient required a clinic review after completion of the episode. This enabled us to compare our sample with previous studies. The interval between the initial consultation and closure of the episode, and the number of patients in each of the groups in fig 2 was

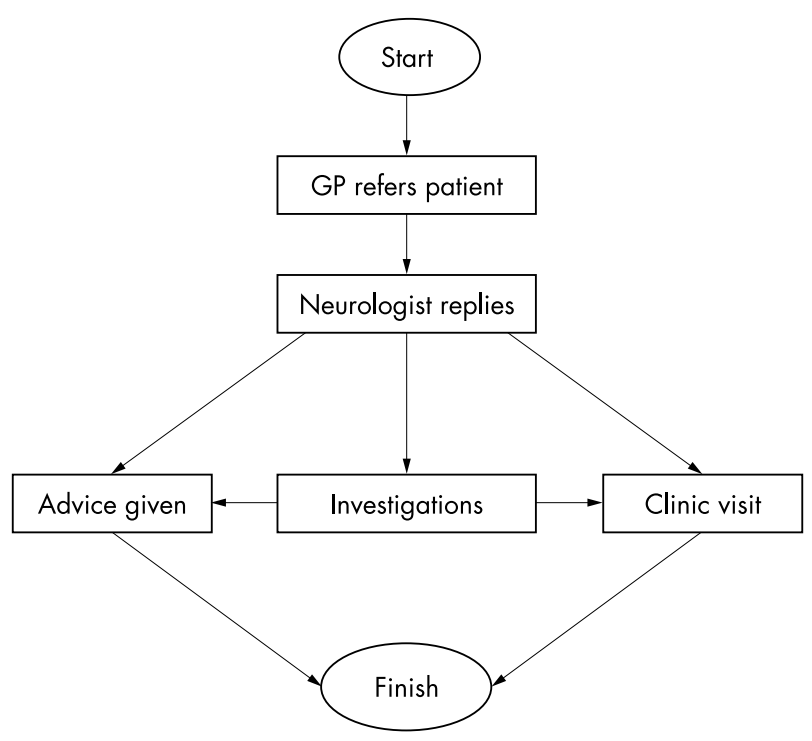

Figure 2 Flow chart of referral process.
Figure 1 Structured form for patient referral. recorded. The closure of the episode was taken as the date of the last email reply for patients managed by email or email plus investigations, and the date of the clinic visit for those patients requiring a visit. The approximate time taken for each email reply was measured and used to calculate the total time of the neurologist.

Satisfaction of the participating GPs was measured by an 8 item questionnaire constructed on a 5 point Likert scale; five questions were about aspects of the process and three about the system as a whole.

To measure initial safety, the medical notes of all patients were reviewed 6 months after the initial consultation. We recorded the following events concerning the original symptom: referral to other specialists, change in diagnosis, hospital admission, and death.

\section{RESULTS}

Seventy six referrals were received for 75 patients in a 14 month period $(27 \mathrm{M}, 48 \mathrm{~F}$, mean age 44 years, range $16-$ 80 years). There were 12 symptoms and 28 different final diagnoses (table 1).

Sixty eight of the 76 queries were replied to within 48 hours and 55 on the same day. The main reason for delay in replying in the other eight emails was breakdown of the NHS email server at the neurologist's teaching hospital.

Thirty four patients (45\% of the total) were managed by advice alone, $9(12 \%)$ required advice and investigations, and 33 were given clinic appointments (43\%).

The time of the neurologist to send one email was 5 minutes and for a subsequent clinic consultation 25 minutes. Time for a conventional consultation without email was taken as 30 minutes, this being the time recommended by 
Table 1 Main presenting symptoms and final diagnosis $(n=76)$

\begin{tabular}{|c|c|c|}
\hline & Total & $\begin{array}{l}\text { Email } \\
\text { advice } \\
\text { only }\end{array}$ \\
\hline \multicolumn{3}{|l|}{ Presenting symptom } \\
\hline Headache & 26 & 15 \\
\hline Sensory disturbance & 16 & 6 \\
\hline Alteration in Consciousness & 7 & 4 \\
\hline Visual/eye disturbance & 6 & 4 \\
\hline Abnormal movement & 4 & 1 \\
\hline Arm pain & 4 & 1 \\
\hline Weakness & 3 & 0 \\
\hline Dizziness & 3 & 1 \\
\hline Mood disturbance & 2 & 1 \\
\hline Speech disturbance & 2 & 1 \\
\hline Unsteadiness & 2 & 0 \\
\hline Memory loss & 1 & 0 \\
\hline \multicolumn{3}{|l|}{ Final diagnosis } \\
\hline Tension headache & 18 & 10 \\
\hline Non-structural disease/stress & 11 & 5 \\
\hline Uncertain & 10 & 6 \\
\hline Epilepsy & 4 & 1 \\
\hline Cervical radiculopathy & 3 & 1 \\
\hline Stroke/transient ischaemic attack & 3 & 0 \\
\hline Anxiety/panic attack & 2 & 1 \\
\hline Carpal tunnel syndrome & 2 & 1 \\
\hline Migraine & 2 & 1 \\
\hline Syncope & 2 & 0 \\
\hline Ulnar neuropathy & 2 & 0 \\
\hline Benign positional vertigo & 1 & 0 \\
\hline Depression & 1 & 1 \\
\hline Horner's syndrome & 1 & 1 \\
\hline Hypoglycaemia & 1 & 1 \\
\hline Meralgia paraesthetica & 1 & 1 \\
\hline Myelopathy & 1 & 0 \\
\hline Neuralgic amyotrophy & 1 & 0 \\
\hline Neurodegenerative disease & 1 & 0 \\
\hline Parkinson's disease & 1 & 0 \\
\hline Post-lumbar puncture headache & 1 & 1 \\
\hline Post-stroke dysaesthesiae & 1 & 1 \\
\hline Post-viral syndrome & 1 & 0 \\
\hline Postural hypotension & 1 & 1 \\
\hline Raeder's syndrome & 1 & 0 \\
\hline Restless legs & 1 & 1 \\
\hline Tic & 1 & 0 \\
\hline Transient global amnesia & 1 & 0 \\
\hline
\end{tabular}

the Association of British Neurologists. ${ }^{6}$ Sixty three patients required one email, and 13 required two; these were the 9 patients who needed investigations (and their results were communicated to the GP by an email from the neurologist) and the 4 patients for whom advice alone was given, but for
Table 2 Total consultation times for new system compared with conventional management

\begin{tabular}{lllll}
\hline System & $\begin{array}{l}\text { Unit time } \\
\text { (mins) }\end{array}$ & No. & $\begin{array}{l}\text { Total time } \\
\text { (mins) }\end{array}$ & $\begin{array}{l}\text { System total } \\
\text { (mins) }\end{array}$ \\
\hline $\begin{array}{l}\text { Conventional } \\
\text { Email triage }\end{array}$ & 30 & 76 & 2280 & 2280 \\
$\quad$ 1st email & 5 & 76 & 380 & \\
$\quad \begin{array}{l}\text { 2nd email } \\
\text { Consultation }\end{array}$ & 5 & 13 & 65 & 1270 \\
\hline
\end{tabular}

Table 3 Investigations performed

\begin{tabular}{lll}
\hline Investigation & $\begin{array}{l}\text { Patients not } \\
\text { seen in clinic }\end{array}$ & All patients \\
\hline CT brain & 6 & 16 \\
NCVE & 2 & 6 \\
EEG & 0 & 3 \\
Brain MRI & 0 & 1 \\
Carotid Doppler & 0 & 1 \\
Plain x ray & 1 & 3 \\
Blood tests & 0 & 7 \\
\hline \multirow{2}{*}{ NCVE, nerve conduction velocities electromyography. }
\end{tabular}

whom the neurologist requested further information from the GP by email. The total time spent was therefore 1270 minutes (mean of 16.7 minutes per patient), a reduction of $44 \%$ on the time that would have been taken had the patients been seen conventionally (table 2 ).

The investigations performed are shown in table 3 . The first column denotes the patients for whom tests were ordered and advice then given without them being seen by the neurologist; all these investigations required hospital attendance. The second column shows those patients who were seen and had tests carried out before or after their appointment. These investigations were carried out in 27 patients $(36 \%)$, the remaining $64 \%$ having no tests. Twelve patients $(16 \%)$ were given follow up appointments.

\section{GP questionnaire}

Eight participating GPs replied (one GP died during the course of the study). Satisfaction was uniformly high, (table 4).

\section{Safety study}

Eight patients were referred by their GP to nine other specialists for further opinions about their original symptoms

\begin{tabular}{|c|c|c|c|c|c|}
\hline & Always & Usually & Sometimes & Rarely & Never \\
\hline $\begin{array}{l}\text { Did you let the patients know about the } \\
\text { email system before sending the email? }\end{array}$ & 8 & 0 & 0 & 0 & 0 \\
\hline waiting time is to see a neurologist? & 1 & 5 & 1 & 1 & 0 \\
\hline $\begin{array}{l}\text { Did you share the email reply with the } \\
\text { patient? }\end{array}$ & 3 & 4 & 1 & 0 & 0 \\
\hline $\begin{array}{l}\text { Do you think the replies were suitable } \\
\text { to be seen by the patient? } \\
\text { I had difficulty when the neurologist }\end{array}$ & 1 & 5 & 2 & 0 & 0 \\
\hline $\begin{array}{l}\text { said the patient didn't need to be seen } \\
\text { l'd rather go back to the old system }\end{array}$ & 0 & 1 & 2 & 5 & 0 \\
\hline of letter referral & 0 & 0 & 0 & 3 & 5 \\
\hline \multirow[t]{2}{*}{ I think this system improves patient care } & 1 & 7 & 0 & 0 & 0 \\
\hline & Easier & The same & Harder & & \\
\hline This system makes my job as a GP & 8 & 0 & 0 & & \\
\hline
\end{tabular}




\begin{tabular}{|c|c|c|c|}
\hline Patient & Referred to* & Original diagnosis & Diagnosis change \\
\hline 1 & ENT & Panic attacks & No \\
\hline 2 & Neurologist & Restless legs & Benign myoclonus \\
\hline 3 & Oral surgeon & Tension headaches & $\begin{array}{l}\text { Temporomandibula } \\
\text { joint dysfunction }\end{array}$ \\
\hline 4 & Orthopaedics & $\begin{array}{l}\text { Cervical } \\
\text { radiculopathy }\end{array}$ & Uncertain \\
\hline 5 & Neurologist & Uncertain & No \\
\hline 6 & Geriatrician & $\begin{array}{l}\text { Stroke, posterior } \\
\text { circulation }\end{array}$ & No \\
\hline 7 & Neurologist & Tension headaches & Migraine \\
\hline 7 & Physician & Tension headaches & No \\
\hline 8 & Neurologist & $\begin{array}{l}\text { Cervical } \\
\text { radiculopathy }\end{array}$ & No \\
\hline
\end{tabular}

(table 5). This resulted in three changes to the original diagnosis, all of a minor nature.

Five patients required hospital admission; four of these were generated by the neurologist for epidural blood patch, investigation of myelopathy, investigation of brain tumour, and investigation of dysarthria respectively. One was admitted to a medical ward after GP referral; no change in diagnosis resulted.

No patients died during the follow up period.

\section{DISCUSSION}

Email correspondence between a GP and a neurologist enables the majority of patients to be dealt with within 3 days of referral, enables $57 \%$ of those referred to be given advice or have investigations arranged without entering the hospital clinic system, and reduces the time of the neurologist by $44 \%$. The participating GPs reported excellent satisfaction levels. Importantly, no significant diagnostic errors were apparent at 6 month follow up.

This study's strength is its real life context. Most GPs would like to refer patients with neurological symptoms to a neurologist; however, in reality neurologists' waiting lists are often much longer than those of other specialities and so many patients with neurological symptoms are referred to general physicians. In a previous study we have shown that such a system is considerably less efficient than referral to a neurologist. ${ }^{7}$ In this study we asked for all such patients to be included; this may explain the higher levels of GP satisfaction. Because of the stable population in the area, we were able to achieve full follow up at 6 months. The safety results are important because of the perceived fear of missing a structural diagnosis when a neurological examination is not performed. Structural disease was relatively frequent in this cohort (23 of 76 patients had structural conditions or epilepsy) so if misdiagnosis of patients labelled as nonstructural had occurred it should have been apparent at the 6 month follow up.

One of the weaknesses of the study was that only a single neurologist was involved so we do not know how generalisable are the results. We also do not know whether the easier availability of the neurologist resulted in referral of patients who would otherwise not have been referred.

There are surprisingly few other studies on the use of email at the primary/secondary care interface. Harno et al compared email with conventional management in general medical patients and found that email improved clinical effectiveness, lowered direct costs, increased productivity, and was cost effective. ${ }^{3}$ However, patients with neurological symptoms were not included in this group (Harno, personal communication). We have used email in a group of extremely complicated neurological inpatients in a rehabilitation hospital in Bangladesh and found it to be effective and of benefit to the referring doctors and their patients. ${ }^{45}$ Indeed, it was the success of that project that gave us the impetus to start this one.

The group of patients seen had a similar mean age and sex ratio to other cohorts of neurological outpatients that we have reported previously. ${ }^{8}$ The percentage of patients having investigations was also similar, but more patients were discharged after the initial visit in the present group. There was significant delay in reply in 8 of the 76 patient encounters, generally caused by the NHS email service being 'down' either at the transmitting or receiving end. This has also been referred to in a previous study. ${ }^{9}$ Private email addresses may be more reliable, and anonymity protocols makes their use possible.

These results imply that email enables neurologists to see more patients in a unit time, which will of course reduce waiting lists. GPs and patients receive a more prompt service and the type of patient seen by the neurologist is more relevant. New patient referrals make up a considerable part of the work of consultant neurologists.

These results need to be confirmed in a randomised control trial; if they are this will have significant implications for how neurologists practise their speciality.

\section{ACKNOWLEDGEMENTS}

We are grateful to the nine general practitioners who participated in this study. Dr J Garvey died tragically during its course. The Northern Ireland Research and Development Office provided financial support. We thank Dr J Craig for helpful comments on earlier drafts of the manuscript.

\section{Authors' affiliations \\ V Patterson, R Chua, Royal Victoria Hospital, Belfast, UK \\ J Humphreys, Erne Hospital, Enniskillen, UK \\ Competing interests: none declared}

\section{REFERENCES}

1 Association of British Neurologists. Neurology in the UK. Towards 2000 and beyond. London: ABN, 1997.

2 Association of British Neurologists. Acute neurological emergencies in adults. London: ABN, 2002.

3 Harno K, Paavola T, Carlson C, et al. Patient referral by telemedicine: effectiveness and cost analysis of an intranet system. J Telemed Telecare 2000;6:320-9.

4 Patterson V, Hoque F, Vassallo D, et al. Store-and-forward teleneurology in developing countries. J Telemed Telecare 2001;7(Suppl 1):52-3.

5 Vassallo DJ, Hoque F, Farquharson Roberts M, et al. An evaluation of the initial year's experience with the first telemedicine link for Bangladesh. J Telemed Telecare 2001;7:125-38.

6 Association of British Neurologists. Neurology in the United Kingdom: good neurological practice. London: ABN, 1998.

7 Esmonde TFG, Patterson VH. Comparison of the handling of neurological outpatient referrals by general physicians and a neurologist. J Neurol Neurosurg Psychiat 1993;56:830.

8 Chua R, Craig J, Esmonde T, et al. Telemedicine for new neurological outpatients: putting a randomised controlled trial in the context of everyday practice. J Telemed Telecare 2002;5:270-3.

9 Graham LE, Zimmerman M, Vassallo DJ, et al. Telemedicine-the way ahead for medicine in the developing world. Trop Doct 2003;33:36-8. 